\title{
Pattern and outcome of pediatric head injuries in the Suez Canal Region: A follow-up study
}

\section{Original Article}

\author{
Hoda Atwa', Nouran B. AbdAllah ${ }^{1}$, Heba Abd El Gawad ${ }^{2}$ \\ ${ }^{1}$ Department of Pediatrics, Faculty of Medicine, Suez Canal University, Suez, Egypt
}

${ }^{2}$ Pediatric Department of Ministry of Health Hospital, Ismailia

\begin{abstract}
Background: A significant number of children sustain a head injury every year. Despite this, few studies in Egypt have provided detailed information about these injuries.

Aim: The aim of this study was to investigate the epidemiology and outcome of head injury among children presenting to the emergency department in the Suez Canal University Hospital.

Materials and Methods: A clinical follow-up study including 70 patients, aged 18 years or less, who presented to the emergency department, with head injuries, in the period from March 2014 to February 2015. Patients were grouped according to their ages into three subgroups: $<2,2-5$, and $>5$ years old. Collected data included patients' demographics, causes, severity, timing of injuries, and the eventual outcome after a follow-up period of 3 months. Severity of head injury was based on the general level of consciousness using the Pediatric Glasgow Coma Scale. The functional outcome at final follow-up was assessed using the King's Outcome Scale for Childhood Head Injury.

Results: Male-to-female ratio was $1.4: 1$. The highest incidence was in the age group of $2-5$ years. The main causes were traffic injury and falls (35.7\% for each), followed by home injuries (21\%) and sport-related injuries (7\%). Regarding the severity of injury, $81 \%$ of children had mild injury, $13 \%$ had moderate injury, and $6 \%$ had severe injury. Concussion was the commonest type of head injury (56\%), followed by skull fractures $(23 \%)$. The functional outcome was assessed at the time of discharge, and 3 months later. Good recovery was achieved in 91\% of children; moderate disability was present in $7 \%$ of children; and less than $2 \%$ of children showed sustained severe disability.

Conclusion: Children aged 5 years or less comprised $75 \%$ of children who presented to the hospital following head injury. Falls and road traffic accidents were the commonest causes of injury. Most injuries were of mild severity, and concussion was the commonest encountered type of injury. Assessment of functional outcome showed good recovery in most children. Enforcement of strict effective regulations and observing safety measures during driving by authorities is needed to reduce traffic accidents. Health education programs for parents about careful supervision and first aid should be provided to help prevent child head injury and its disastrous consequencest.
\end{abstract}

Received: 14 November 2016, Accepted: 12 January 2017

Key Words: Head injury, pediatric, severity.

Corresponding Author: Nouran B. AbdAllah, MD, Department of Pediatrics, Faculty of Medicine, Suez Canal University, Suez, Egypt, Tel.: +20 100490 3264, E-mail: nouranboym2@hotmail.com.

ISSN: 0013-2446, Vol. 92, No.1

\section{INTRODUCTION}

Head injury is recognized as a major public health problem that is a frequent cause of death and disability in young people, and makes considerable demands on health services ${ }^{[1]}$. Traumatic head injury is defined as an acquired injury to the head, caused by an external physical force, resulting in total or partial functional disability or psychosocial impairment, with an associated altered state of consciousness. Types of head injury include scalp injury, skull fracture, concussion, contusion, intracranial or subarachnoid hemorrhage, epidural or subdural hematoma, intraventricular hemorrhage, and diffuse axonal injury ${ }^{[2]}$. The injury commonly causes a variety of physical, emotional, cognitive, and behavioral impairments ${ }^{[3]}$.

Head injury in children accounts for a large number of emergency department visits and hospital admissions, and remains a major cause of death and disability in children over 1 year of age ${ }^{[2]}$. Approximately $75 \%$ of children admitted to hospitals with injury have a head injury, and $70 \%$ of injury deaths are due to head injuries in the USA ${ }^{[4]}$. In industrialized countries, traumatic brain injuries affect $191 / 100000$ children annually in persons aged 0-19 years ${ }^{[5]}$. The WHO notes that $98 \%$ of all child injury mortality occurs in the world's poorest countries, and the rate of these deaths is five times higher than among industrialized nations ${ }^{[6]}$. Children in developing countries are especially vulnerable to injury due to challenging living conditions, increasing road traffic, lack of safe play areas, and absence of childcare options $\mathbf{s}^{[7,8]}$.

Comprehensive information about pediatric head injuries is necessary for planning management strategies 
and intervention priorities that can respond effectively and appropriately to local conditions, and is recognized by the WHO as a key priority for strategic research ${ }^{[9-11]}$. Unfortunately, the epidemiology of pediatric traumatic head injuries is difficult to be adequately described mainly due to inconsistency of the definition and classification. Patients with mild traumatic brain injury may not present to the hospital and the ones who present may be discharged from the emergency department without adequate documentation. Severe injury may result in death at the place of accident. Differences in data collection tools and admission criteria may also cause discrepancies in collected data $^{[12]}$. In Egypt, besides these difficulties, epidemiological data and updated statistical records for pediatric traumatic head injuries are often lacking and difficult to extract from routinely collected data ${ }^{[13]}$.

In this study, we describe the epidemiology of pediatric head injury in the Suez Canal Region, highlighting on the patient's demographics, nature and etiology of injuries, clinical presentation, and the functional outcome of children attended at the Suez Canal University Hospital suffering head injury.

\section{MATERIALS AND METHODS}

The study is a clinical follow-up study including 70 children aged 18 years or less, who presented at the Emergency Department of Suez Canal University Hospital, Ismailia, Egypt, after sustaining a head injury from March 2014 to February 2015. Children were examined at the time of presentation in the emergency department and they were followed up for a 3-month duration. Our hospital is a referral hospital; patients from the whole Suez Canal Region attend the emergency department.

Patients were grouped according to their ages into three subgroups: $<2,2-5$, and $>5$ years old. Severity of head injury was based on the general level of consciousness using the Pediatric Glasgow Coma Scale (PGCS) with the following criteria; mild: PGCS of 13-15, and an indication of altered consciousness; moderate: PGCS of 9-12, an indication of altered consciousness and reduced responsiveness; severe: PGCS of 3-8, representing coma or altered consciousness ${ }^{[14]}$.

\section{Inclusion criteria}

All individuals under 18 years old of both sexes who experienced one or a combination of head trauma were targeted in the study. Head trauma included scalp injury, skull fracture, concussion, contusion, intracranial hemorrhage, penetrating injury, and diffuse axonal injury.
Diagnosis was confirmed clinically and radiologically.

\section{Exclusion criteria}

Patients declared dead on arrival, patients with preexisting neurological disorders or bleeding disorders, and child abuse trauma were excluded.

The information collected included demographic information (age, sex, residence), information about head injury (time, type, location, cause, and severity of injury), and clinical symptoms (loss of consciousness, vomiting, drowsiness, etc.), computed tomography (CT) findings, further management, and functional outcome at final follow-up using the King's Outcome Scale for Childhood Head Injury ${ }^{[15]}$. Our sample included all children presenting to the emergency department during the period from March 2014 to February 2015

\section{Statistical analysis}

Statistical analysis was performed using the statistical package for the social sciences (version 20; IBM Corp., Chicago, Illinois, USA). Continuous variables were expressed as mean and SD. Discrete variables were expressed as frequencies and percentages. Quantitative data analysis was performed using $\chi 2$-test, Fisher's exact test, and Student's t-test as appropriate. P values of 0.05 or less were regarded as significant. Differences were statistically significant if $p$ value is less than or equal to 0.05 .

\section{Ethical consideration}

Ethical approval declaring agreement with the principles in the Declaration of Helsinki was obtained from the Suez Canal University Ethics Council prior to the study. The parents of children gave their verbal consent to participate in this study.

\section{RESULTS}

Head injuries were most common among boys $(41,59 \%)$, with a male/female ratio equal to $1.4: 1$. The highest incidence of head injuries occurred in children aged less than 5 years $(53,75.7 \%)$, with most head injuries among the $2-5$-year age group $(33,47 \%)$. The mean age at injury was 4.29 years $(\mathrm{SD}=3.9$, range: 3 months -16 years). Most children were resident in urban areas $(46,65 \%)$. More than half $(56 \%)$ of the children have had their head injuries outdoors, and most observed injuries (63\%) occurred during daytime while children were at play, or during school time. Most children (59\%) arrived at hospital by private vehicles, and the remainder (41\%) arrived by ambulances. Most children $(82 \%)$ arrived at hospital accompanied with one of their parents (Table 1). 
Table 1: Demographic data of children with head injury, Suez Canal Region, Egypt (2014-2015)

\begin{tabular}{|c|c|}
\hline Demographic data & $\mathrm{N}=70[\mathrm{n}(\%)]$ \\
\hline \multicolumn{2}{|l|}{ Sex } \\
\hline Female & (41) 29 \\
\hline Male & (59) 41 \\
\hline \multicolumn{2}{|l|}{ Age (years) } \\
\hline$<2$ & (28.8) 20 \\
\hline $2-5$ & (47) 33 \\
\hline$>5$ & (24.2) 17 \\
\hline \multicolumn{2}{|l|}{ Residency } \\
\hline Urban & (65) 46 \\
\hline Rural & (35) 24 \\
\hline \multicolumn{2}{|l|}{ Injury place } \\
\hline Outdoors & (56) 39 \\
\hline Indoors & (44) 31 \\
\hline \multicolumn{2}{|l|}{ Injury time } \\
\hline Daytime & (63) 44 \\
\hline \multicolumn{2}{|c|}{ Mode of transport to hospital } \\
\hline Private vehicle & (59) 41 \\
\hline Ambulance & (41) 29 \\
\hline \multicolumn{2}{|l|}{ Companion at arrival } \\
\hline Parents & (83) 58 \\
\hline Relatives or foreigner & (17) 12 \\
\hline
\end{tabular}

There was predominance of falls and road traffic accidents as primary causes of injury, and both resembled the cause of injury in $72 \%$ of children. Home injuries were present in $21 \%$ of patients, most of them in the $2-5$-year age group, while sport-related injuries were the cause in $7 \%$ of overall children. There was a significant association between cause and age group $(\chi 2=18.03$ and $p<0.05)$ (Table 2).

Table 2: Cause of head injury by different age groups, Suez Canal Region, Egypt (2014-2015)

\begin{tabular}{|c|c|c|c|c|}
\hline \multirow[t]{2}{*}{ Cause of injury } & \multicolumn{4}{|c|}{ Age groups $[\mathrm{n}(\%)]$} \\
\hline & $\begin{array}{l}<2 \text { years } \\
\mathrm{N}(\%)\end{array}$ & $\begin{array}{c}2-5 \text { years } \\
\text { N (\%) }\end{array}$ & $\begin{array}{c}>5 \text { years } \\
\text { N (\%) }\end{array}$ & $\begin{array}{c}\text { Total }(\mathrm{N}=70) \\
\mathrm{N}(\%)\end{array}$ \\
\hline Road traffic accident & $3(12)$ & $13(52)$ & $9(36)$ & $25(35.7)$ \\
\hline Fall & $14(56)$ & $10(40)$ & $1(4)$ & $25(35.7)$ \\
\hline Home injury & $3(20)$ & $7(47)$ & $5(33)$ & $15(21.4)$ \\
\hline Sport-related & $0(0)$ & $3(60)$ & $2(40)$ & $5(7.1)$ \\
\hline Total & $20(28.6)$ & $33(47)$ & $17(24.2)$ & $70(100)$ \\
\hline
\end{tabular}

$\chi 2=18.03$, and $\mathrm{P}=0.0061$. 
Concussion was the commonest recorded type of head injury, it was present in 56\% of cases, followed by skull fractures in $23 \%$, brain contusions and extradural hematoma in $4 \%$ for each, and intracerebral hematoma in $3 \%$ of children as shown in Fig. 1

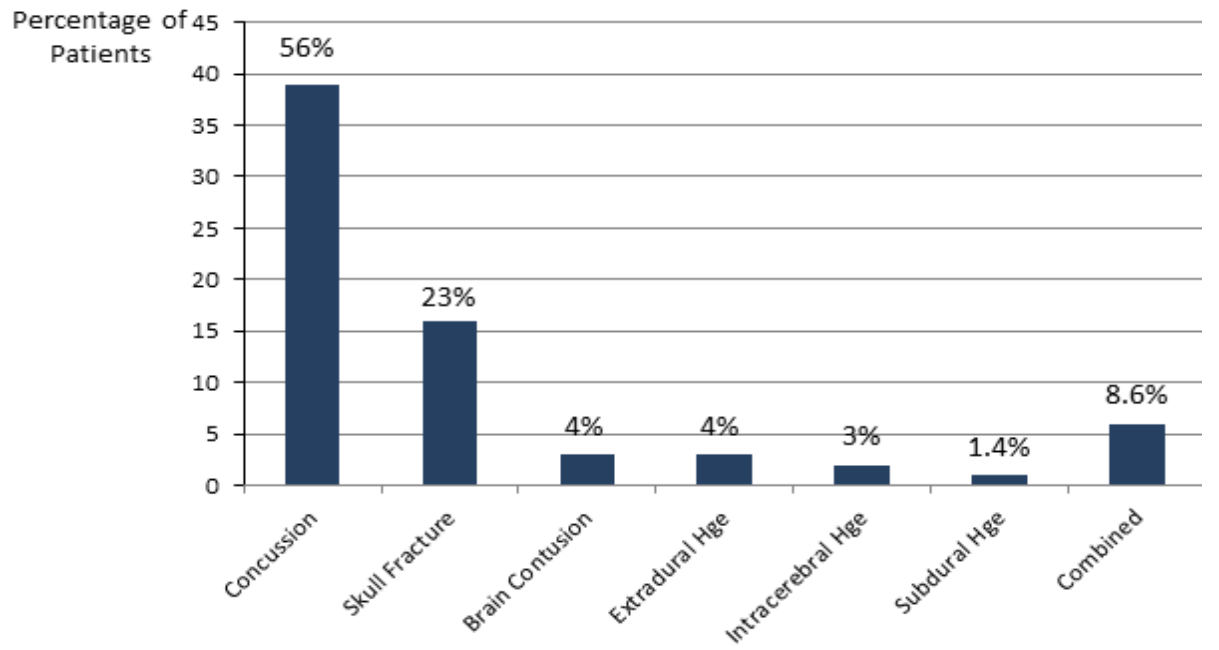

Fig. 1: Distribution of types of head injury, Suez Canal Region, Egypt, 2014-2015.

Regarding severity of head injury, most children $(81 \%)$ had mild injury, $13 \%$ had moderate injury, and $6 \%$ had severe injury. Clinically, $64 \%$ of patients were fully conscious and alert at presentation with a Glasgow Coma Scale equal to 15 . Moderate to severe coma was reported in $19 \%$ of patients. Loss of consciousness was reported in $47 \%$ of children as presenting manifestation in the emergency room; signs of increased intracranial pressure were present in $41 \%$, deficits including mono/hemiparesis, facial palsy, or aphasia in $11 \%$, signs of lateralization in $10 \%$, and abnormal pupillary response in $9 \%$ of children. Most children showed normal CT brain, while $40 \%$ of CT studies showed pathological findings in the form of skull fractures $(42 \%)$, brain edema or brain contusions (14\%) for each, extradural or intracerebral hematoma (4\%) for each, and subdural hematoma in $4 \%$ of these pathological scans.
On follow-up, the majority of children (61\%) were subjected to a $24-\mathrm{h}$ observation and then discharged; $21 \%$ were in need for inpatient ward admission; $12 \%$ were critically ill, and were admitted in the ICU. A minority comprising 6\% of children were subjected to neurosurgical interventions mainly for evacuation of intracranial bleeding.

Functional outcome after head injury was assessed at the time of discharge from hospital, and a final followup after 3 months using the King's Outcome Scale for Childhood Head Injury. It showed the following: 91\% of children showed good recovery, $7 \%$ showed moderate disability, and less than $2 \%$ showed severe disability (Table 3). However, the final functional outcome showed no association with patient's ages or severity of head injury.

Table 3: Early and late King's Outcome Scale for Childhood Head Injury (KOSCHI) in relation to different age groups in pediatric head injuries, Suez Canal Region, Egypt, 2014-2015

\begin{tabular}{|c|c|c|c|c|c|c|}
\hline Outcome & & $\begin{array}{c}<2 \text { Years } \\
(\mathrm{n}=20) \\
\text { No. }(\%)\end{array}$ & $\begin{array}{c}2-5 \text { Years } \\
(n=33) \\
\text { No. }(\%)\end{array}$ & $\begin{array}{c}>5 \text { Years } \\
(\mathrm{n}=17) \\
\text { No. }(\%)\end{array}$ & $\begin{array}{c}\text { Total }(\mathrm{n}=70) \\
\text { No. }(\%)\end{array}$ & \\
\hline \multirow{2}{*}{ Good Recovery } & Early & $20(100)$ & $24(72)$ & $14(82)$ & $58(83)$ & $\mathrm{X} 2=0.146$ \\
\hline & Late & $20(100)$ & $28(84)$ & $16(94)$ & $64(91)$ & $P=0.929$ \\
\hline \multirow{2}{*}{ Moderate Disability } & Early & $0 \quad(0.0)$ & $6(18)$ & $2(11)$ & $8(11)$ & $\mathrm{X} 2=0.043$ \\
\hline & Late & $0 \quad(0.0)$ & $4(12)$ & $1(05)$ & $5(7)$ & $P=0.835$ \\
\hline \multirow{2}{*}{ Severe Disability } & Early & $\begin{array}{ll}0 & (0.0)\end{array}$ & $3(9)$ & $1(05)$ & $4(6)$ & $\mathrm{X} 2=0.312$ \\
\hline & Late & $0 \quad(0.0)$ & $1(3)$ & $0(00)$ & $1(01)$ & $P=0.576$ \\
\hline Total & & 20 & 33 & 17 & 70 & \\
\hline
\end{tabular}

Early: 24 hours, Late: 3 months 


\section{DISCUSSION}

Clinical features of head trauma in pediatrics is similar in many countries. However, comprehensive information about regional head trauma epidemiology is necessarily needed for planning management strategies and intervention priorities ${ }^{[1]}$. Our study comprised all children $(n=70)$ who were attended at the emergency department during the 1-year period from March 2014 to February 2015, in the Suez Canal University Hospital, and suffering head injury. There was some predominance of boys over girls (male/female $=1.4: 1$ ), which is in keeping with other studies throughout the world ${ }^{[15,16]}$. This can be attributed to the more adventurous and aggressive behavior of boys. The majority of injured children were in the 2-5-year age group. This is possible because in this age, children are more independent and are starting to explore the environment, but may have not yet fully learned to assess the risks in their surroundings ${ }^{[16]}$.

The main causes of injury were traffic injury and falls, and both accounted for about $72 \%$. Traffic injury and falls were the most common causes in other studies, accounting for approximately three-quarters to four-fifths of all head injuries in the studies ${ }^{[17-19]}$. In our study, falls were frequent in children younger than 2 years old, while traffic injury was frequent in the 2-5-year old age group. Some studies indicated that in younger ages, falling is more common, and there was a positive relation between increasing age and prevalence of motor accident. The vulnerability of children on the street may be because of the relative imbalance of strength and coordination in childhood ${ }^{[18-20]}$. More than half $(56 \%)$ of children have had their head injuries outdoors. This is most probably due to the fact that older children spend more time outdoors (e.g. playing), whereas younger ones are mostly confined indoors. Jamison and Kaye found that over half the injuries occurring outdoors occurred mainly with children that are less likely to be under direct parental supervision ${ }^{[21]}$.

Osmond et al. ${ }^{[22]}$ stated that $\mathrm{CT}$ of the brain is a valuable investigation tool for the diagnosis and management of pediatric head injuries. In this study, CT scan of the brain was done for all children because the clinical predictors of positive CT findings unfortunately have low sensitivity in pediatrics ${ }^{[23]}$. About $40 \%$ of children had abnormal features in their scans such as skull fracture, brain edema, or hemorrhage. Although this method can help the physician to diagnose more confidently, yet, due to its side effects, special indications for CT scan with the lowest complications in children were set ${ }^{[24]}$.

Concussion was the commonest encountered type of head injury, followed by skull fractures and intracranial bleeds. In most studies, concussion was the predominant type of head injury in children ${ }^{[13,17,25]}$. However, diagnosis is often challenging because signs and symptoms of concussion can be subtle, and may not be easily identified $^{[26]}$.

In this study, severity of head injuries was distributed as follows: $81 \%$ mild, $13 \%$ moderate, and $6 \%$ had severe head injury in contrast to the study performed in Alexandria University Hospital by Kamel ${ }^{[27]}$. Mild head injury was present in $50 \%$ of the children, moderate in $37 \%$, and severe in $13 \%$. There were statistically significant differences for head injury severity in different age groups. The statistics of the Centers for Disease Control and Prevention of Traumatic Head Injury in USA, in 2013 reported that severity among children ranges between 80 and $90 \%$ for mild, $7-8 \%$ for moderate, and $5-8 \%$ for severe traumatic brain injury ${ }^{[28,29]}$.

The relation between childhood traumatic head injury and functional outcome is complex, and to a large extent remains unexplained even after grouping children into traditional classifications according to their ages, or the severity of their injury ${ }^{[30]}$. In our study, the majority of children showed good recovery without any residual deficits. Good recovery was achieved in $91 \%$ of children, moderate disability was present in $7 \%$ of children, and less than $2 \%$ of children showed sustained severe disability. Anderson and colleagues reported that the factors which have been shown to predict the functional outcome were: the severity of injury, location of injury, age at the time of injury, time since injury, family factors, and the premorbid function of the child ${ }^{[31,32]}$.

\section{LIMITATIONS}

Our study limitations are mainly related to the small sample size and hence the difficulty to study the relationship between the type, severity, and outcome of injury and the sociodemographic characteristics of the children. Also, we did not follow-up our patients in terms of behavioral or cognitive changes.

\section{CONCLUSION}

Children under 5 years of age suffer more frequently head injuries caused by traffic injury and falls. Most injuries were mild in severity, and children did not need significant medical intervention. The majority of children achieved good recovery at the end of follow-up. It is important to minimize all the risk factors in the environment of homes and public areas as possible. There is need for stricter enforcement of laws, especially on the use of protective devices and helmet use, compliance with speed limits, and the development of safe public transportation for the prevention of head injury. Health education programs for parents to improve their knowledge about childhood head injury causes, preventive measures, and first aid should be implemented to emphasize the importance of parental/ caregivers' supervision. 


\section{CONFLICT OF INTEREST}

There are no conflicts of interest.

\section{REFERENCES}

1. Danov R. Pediatric traumatic head injuries. In: Slobounov S, Sebastianelli WJ, editors. Foundations of sport-related brain injuries. Boston, MA: Springer US; 2006. pp. 291-314.

2. Parkin P, Maguire J. Clinically important head injuries after head trauma in children. Lancet 2009; 374: 1127-1129.

3. Sumich AI, Nelson MR, McDeavitt JT. Traumatic brain injury: a Pediatric Perspective. In: Zasler N, Katz DI, Zafonte RD, editors. Brain injury medicine: principles and Practice. New York, NY: Demos Medical Publishing; 2007. pp. 305-313.

4. Jagannathan J, Okonkwo D. Long-term outcomes and prognostic factors in pediatric patients with severe traumatic brain injury. J Neurosurg Pediatr 2008; 2: 240-249.

5. Quayle K, Holmes J, Kuppermann N. Epidemiology of blunt head trauma in children in U.S. emergency departments. N Engl J Med 2014; 371: 1945-1947.

6. Arias E, MacDorman MF, Strobino DM. Annual summary of vital statistics. Pediatrics 2003; $112: 1215-1230$

7. Keenan HT, Bratton SL. Epidemiology and outcomes of pediatric traumatic brain injury. Dev Neurosci $2006 ; 28: 256-263$.

8. Collins C, Comstock R. Epidemiology of pediatric injuries presenting to emergency department. Pediatrics 2010; 125: 931-937.

9. Husum H, Wisborg T. Rural prehospital trauma systems improve trauma outcome in low-income countries. J Trauma 2003; 54: 1188-1196.

10. World Health Organization. International Classification of Functioning, Disability and Health. Geneva, Switzerland: WHO; 2001.

11. Critchley G, Memon A. Epidemiology of head injury. In: Whitfield P, Thomas E, editors Head injury: a multidisciplinary approach. Cambridge, UK: Cambridge University Press; 2009. pp. 1-4

12. Montaser T, Hasan A, Ibrahim A. Epidemiology of moderate and severe traumatic brain injury in Cairo
University Hospital in 2010. Scand J Trauma Resusc Emerg Med 2013; 21(Suppl 2): 320.

13. Halawa EF, Barakat A, Ibrahim H, Moawad E. Epidemiology of non-fatal injuries among Egyptian children:a community based cross-sectional survey. BMC Public Health 2015; 15: 1248.

14. Anderson V, Catroppa C, Haritou F. Identifying factors contributing to child and family outcome in children. J Neurol Neurosurg Psychiatry 2005; 76: 401-408.

15. Crouchman M, Rossiter L, Colaco T. A practical outcome scale for pediatric head injury. Arch Dis Child 2001; 84: 120-124.

16. Yeates KO, Taylor HG. Neurobehavioural outcomes of head injury in children and adolescents. Pediatr Rehabil 2005; 8: 5-16.

17. Elsayed HF, Zekry MO, Abbas HM, Abdelhamid S, Hyder A. Pattern and severity of childhood unintentional injuries in Ismailia city, Egypt. Afr Saf Promot J 2012; 10: 18-27.

18. World Health Organization and Ministry of Health (Egypt). Injury surveillance: a tool for decision making. Annual Injury Surveillance Report, Egypt. Geneva, Switzerland: WHO; 2009.

19. Razzak J, Luby S, Laflamme L, Chotani H. Injuries among children in Karachi, Pakistan, what, where and how. Public Health 2004; 118: 114-120.

20. Paget SP, Beath AW, Barnes EH, Waugh MC. Use of King's Outcome Scale for Childhood Head Injury in the evaluation of outcome in childhood traumatic brain injury. Dev Neurorehabil 2012; 15:171-177.

21. Jamison DL, Kaye HH. Accidental head injury in childhood. Arch Dis Child. 1974;49: 376-381.

22. Osmond M, Klassen T, Wells G. A clinical decision rule for the use of computed tomography in children with minor head injury. CMAJ 2010; 182:341-348.

23. Maguire J, Boutis K, Uleryk E. Should a head injured child receive a head CT scan? A systematic review of clinical prediction rules. Pediatrics 2009; 124: $145-154$

24. Atci B, Albayrak S, Durda E. Retrospective analysis of 11383 patients admitted to the emergency department with head trauma within 2 years. Internet $\mathbf{J}$ Emerg Med 2013; 8: 127-134.

25. Mahapatra A. Head injury in children. In: Mahapatra 
A, Kamal R, editors. A text book of head injury. Delhi, India: Modern Publications; 2004. pp. 156-170.

26. Bazarian J, Veenema T, Brayer A. Knowledge of concussion guidelines among practitioners caring for children. Clin Pediatr 2001; 40: 207-212.

27. Kamel HE. Study of head injuries in young children [Thesis]. Alexandria, Egypt: Faculty of Medicine, Alexandria University; 2016.

28. Mannix R, Florence TB, Lois K. Neuroimaging for pediatric head trauma: do patient and hospital characteristics influence who gets imaged? Acad Emerg Med 2010; 17: 694-700.
29. Centers for Disease Control and Prevention. National Center For Injury Control And Prevention: how many people have TBI?; 2013 [cited 2016 Dec 12]. Available at: http//www.cdc.gov/traumatic brain injury/statistics.

30. Dhandapani SS, Manju D, Mahapatra AK. Prognostic significance of age in traumatic brain injury. J Neurosci Rural Pract 2012; 3: 82-100.

31. Taylor G. Research on outcomes of pediatric traumatic brain injury. Dev Neuropsychol 2004; 25: 199-225.

32. Anderson V, Spencer-Smith M, Leventer R. Childhood brain insult: can age at insult help us predict outcome? Brain 2009; 132: 45-56. 